\title{
Special Design of Ski Plates May Improve Skiing Safety
}

\author{
Matej Supej and Veit Senner
}

\begin{abstract}
Background: Alpine skiing is a popular winter sport that is confronted with high injury rates. Ski bindings are often mounted on ski plates, which can positively affect the release consistency of ski bindings and thus improve skiing safety. The aim of the study was to explore, if a new ski plate design of which the middle main part was "floating" on rocker arms improved the release consistency of ski bindings when the ski was deflected.

Method: In order to test the new ski plate, three pairs of equal slalom skis were equipped with identical ski bindings. They were mounted: (1) directly to the ski, (2) on the original ski plate, and (3) on the new ski plate. The forward bending release and the torsion release behaviour of these three ski-plate-binding set-ups were tested on a standardized testing device under three conditions: a flat ski, skideflection according to the ISO-standard and an extreme ski-deflection.

Results: One-way ANOVA with Tukey post hoc test revealed that all comparisons among different mountings of the binding under three conditions, except in three occurrences when comparing no plate versus new plate, were significantly different. In addition, the new ski plate demonstrated a more consistent torsion release behaviour with almost no shift in the release load $(\sim-1.5 \%)$ for both tested ski-deflections. The majority of relative differences ranged between 6.9 and $8.2 \%$ between the three tested mounting conditions with respect to the forward release.

Conclusion: Mounting ski bindings on specially designed ski plates may result in an improved release behaviour and thus potentially increase skiing safety.
\end{abstract}

Keywords Alpine skiing • Ski plates $\bullet$ Ski bindings $\bullet$ Injury prevention • Tibia fractures

\footnotetext{
M. Supej $(\bowtie)$

University of Ljubljana, Faculty of Sport, Gortanova 22, 1000 Ljubljana, Slovenia

e-mail: matej.supej@fsp.uni-lj.si

\section{Senner}

Technical University of Munich (TUM), Sports Equipment and Materials,

Boltzmannstraße 15, D-85748 Garching, Germany
} 


\section{Introduction}

Alpine skiing is a popular outdoor winter sport in many countries with approximately 400 million skier visits worldwide [1]. In competitive alpine skiing, skiers, on the one hand, strive to optimize their skiing by optimizing several different mechanical predictors such as time, speed, turn radius and energy dissipation [2-4]. Several of these parameters are, on the other hand, recognized as major risk factors for injuries in competitive skiing [5-8]. It is therefore no surprise that injury rates for competitors are very high [9].

The injury rates are very high also in recreational alpine skiing with a range from 2.4 to 7.0 injuries per 1000 activity days [10]. Alpine skiing was stated to be "the riskiest sport undertaken by adults on a routine basis" [11]. Both, in competitive as well as in recreational skiing the highest rate of injuries is connected to the knee joint [12-14]. The injury rate in the knee joint remains at a high level since the midnineties [15], only the MCL (medial collateral ligament)-knee injuries seem to have slightly decreased over the 18 investigated seasons [16]. The reduced ski length generally explains this levelling-off since the introduction of carving skis $[15,17]$.

With the background of this unchanged high knee injury rate a recent study investigated the potential role of the ski-binding-boot functional unit to decrease the injury risk of lower extremities [18]. It concluded that the biggest potential to decrease the injury rate was to develop more sophisticated safety release bindings, i.e. introducing a mechatronic design. Among others, it was pointed out that the reduction in the influence of constraining forces on the release behaviour of the bindings could be achieved by the intervention in the appropriate design of sliding elements and bearings.

In order to explain the relationship between the inadvertent release and no release when necessary, a Signal Detection Theory (SDT) has been introduced [19]. SDT describes normal load (NL) and injury load (IL). The NL represents the area when no release is needed and the IL when the release is needed. In addition, there is also a probability when (1) a failure to release and (2) the inadvertent release appears. In general, these two probabilities are desired to be as small as possible in order to yield safer bindings for a target population group. Therefore, any attempt that can help providing a decrease in the inadvertent release without affecting the appropriate release is considered beneficial for skiing safety.

Ski plates have been primarily propagated to influence a bending line and the damping behaviour of the ski as well as the boot-out at large ski inclinations [18]. Recently, a platform for mounting the binding on a ski (Allflex plate, Allflex ski and snowboard plates, Slovenia) with a unique patented construction [20] has been introduced to the market. It has been designed in such a way that the middle rigid part holding the ski bindings is connected to the ski with two rigidly anchored vertical rocker arms at the front and at the back as well as two horizontal rocker arms in the middle of the plate (Fig. 1). Vertical rocker arms at the front and at the back function as compensatory parts, cancelling the shortening of the ski's upper surface when the ski is deflected. The two double horizontal rocker arms in the middle part 


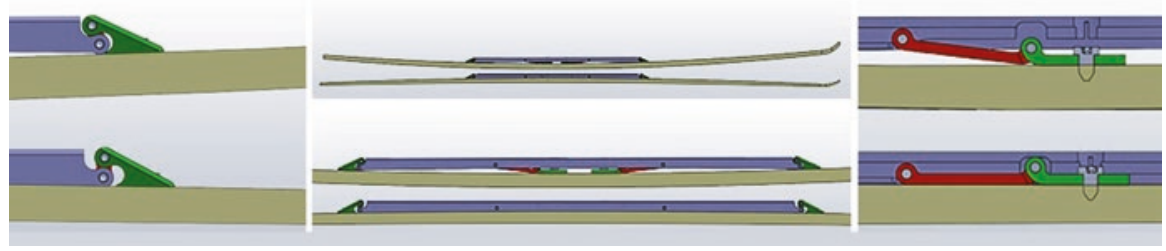

Fig. 1 A new ski plate (middle) with two vertical rocker arms at the front and at the back (left) as well as two horizontal rocker arms in the middle ( $r i g h t$ ). In all parts of the figure, the bottom drawing represents a plate mounted on an unloaded ski (stretched ski) and the top one mounted on ski which is loaded and consequently deflected

act synchronously with the vertical rocker arms and avoid moving the middle rigid part of the plate forward and backward along the skis. This construction of ski plate intends to decrease the constrained forces on the ski binding when the ski is deflected and should - according to the SDT theory-improve the release behaviour [19, 21].

Therefore, the aim of this study was to explore, if the new ski plate design where the middle main part of the plate was "floating" on rocker arms, improved the release consistency of ski bindings when the ski was deflected.

\section{Methods}

An alpine ski binding should fulfil two main functions. It should ensure a firm connection between the ski boot and the ski and release the ski if there is an excessive load that could potentially cause an injury to the leg. In practice, the ski binding is exposed to three-moment and three-force components. Ideally, the ski bindings should have a release mechanism that can be triggered by any of these mechanical parameters at excessive (injury level) loads [18]. The official requirements and test methods for the ski bindings are described by the International Standardization Organization (ISO) under the ISO 9462:2014 standard.

In order to test the new ski plate, three pairs of equal Elan Slalom skis (Race SLX World Cup M52, length $165 \mathrm{~cm}$-FIS approved) selected based on their mechanical properties $(<1 \mathrm{~mm}$ tolerance in camber height of the unloaded ski and $<3 \%$ difference in the ski-deflection distance in as standard bending test with $300 \mathrm{~N}$ applied force) were equipped with the identical Elan (ER 17.0 Free Flex PRO) ski bindings. The bindings were mounted in three different ways (Fig. 2):

- Directly to the ski without any additional ski plate (no plate)

- On the (supplemental) "original ski plate" (Tyrolia Raceplate RDX)

- On the "new ski plate" (Allflex plate)

The new ski plate was considerable differed from the original ski plate and consisted of two pieces per ski. Each piece of the original plate was on a distal side fixed by using a screw over the oblong hole. This allowed movements/flexibility of the ski under the plate as it is common in "classic" plate designs. 


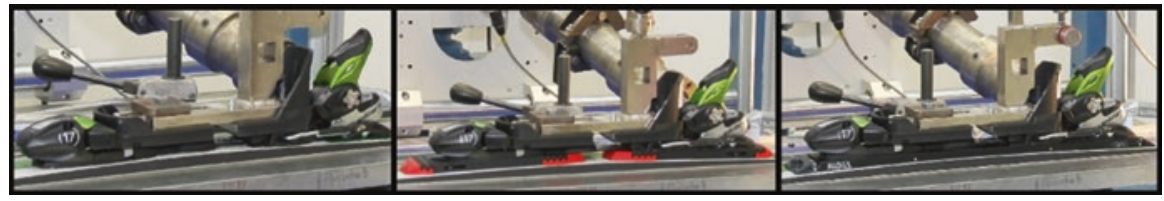

Fig. 2 The bindings mounted directly to the ski without any additional ski plate (left), on the original ski plate (Tyrolia Raceplate RDX; middle) and on the new ski plate (Allflex plate; right)
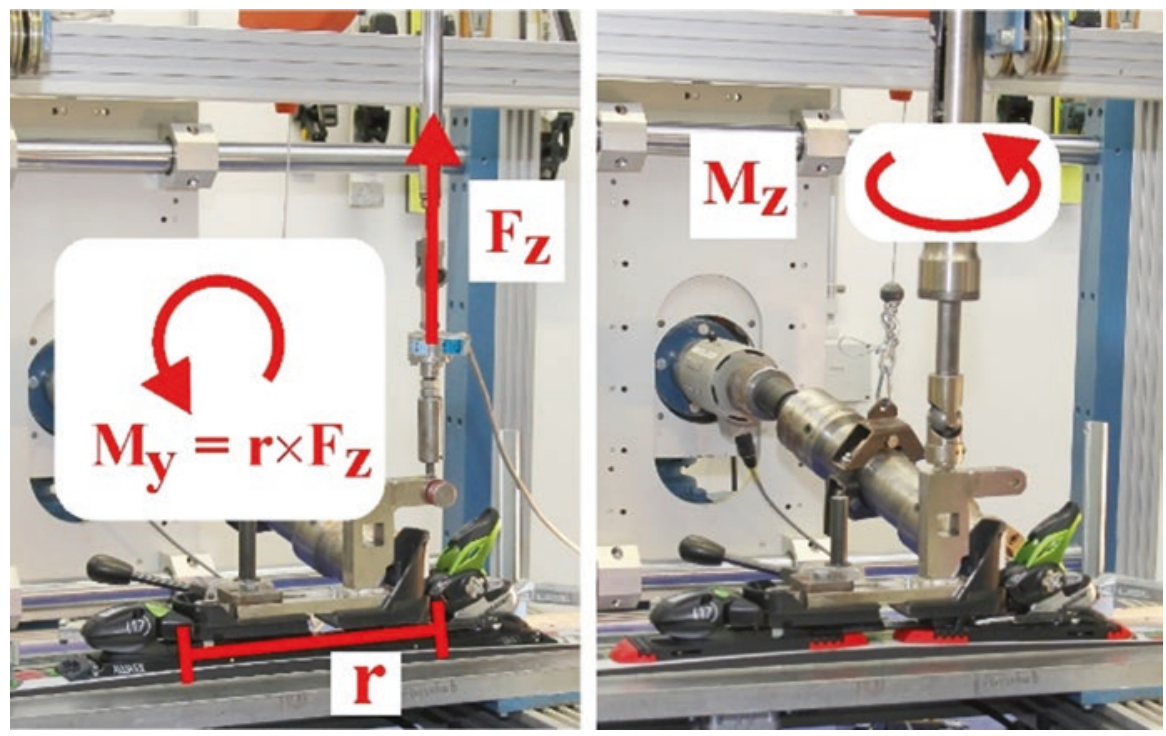

Fig. 3 The forward bending release (left) and torsion release (right) test on an ISO 9462 Method A testing device at TÜV Product Service $\mathrm{GmbH}$, Munich, with a ski clamped to the ground (flat ski). $F z$ vertical force; $r$ lever (sole length); $M y$ forward bending release torque; $M z$ torsion release torque

In order to smooth the bearings to run the systems at minimum friction, these three ski-plate-binding set-ups were skied 5 days for 10-15 runs by a ski tester, former member of the Slovenia Alpine Ski Demo Team prior to the release behaviour tests.

The release behaviours were tested on a standardized testing device (TÜV Product Service GmbH, Munich, Germany; Fig. 3), where the ski was rigidly connected to the test frame and the quasi-static torque or force were progressively applied to the sole until the binding released (Test Method A, ISO 9462:2014). First, the release values on all ski-plate-binding set-ups were set to the same value $(Z=8)$ according the standard on the bindings scale. Thereafter, the reference values were verified and adjusted by a series of tests on a flat ski according to the standard procedure in order to achieve the same "true" initial settings for all ski bindings. Thereafter, two tests were performed (Fig. 3): 

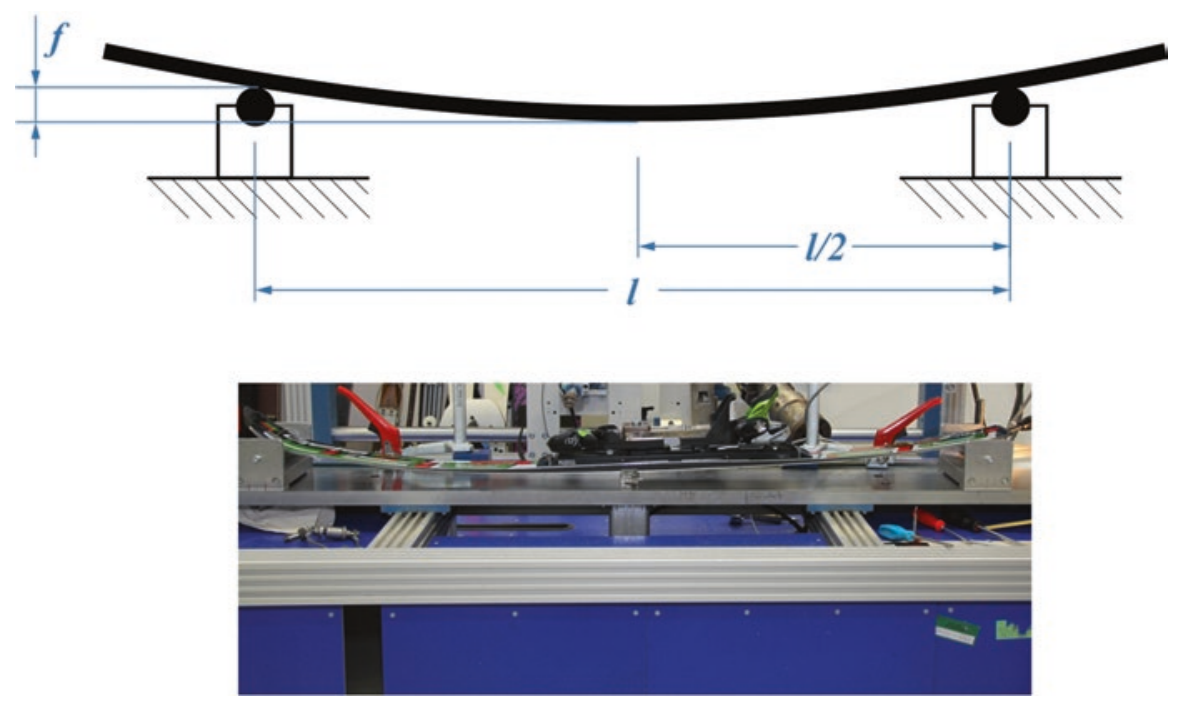

Fig. 4 ISO 9462 Method A testing device (TÜV), during a modified forward bending release test with standard ski-deflection of the ski equipped with the new ski plate (bottom) and the corresponding scheme of the support and deflection distance (top). $l$, distance between the supports; $f$, deflection distance

1. A modified "forward bending release test": applying vertical force Fz at the heel part of the binding resulting in a combined loading of torque My about the horizontal (medio-lateral) axis and a vertical (upright directed) force

2. The ISO compliant standard "torsion release test": applying the torque Mz about the vertical axis

The reason for the modified ISO forward bending release test (note that in the ISO 9462 procedure, only pure moments without any extraneous forces have to be applied) was that this was expected to be the worst-case scenario for the new plate. The vertical force in this test pulled the plate away from the ski under such loading.

Both tests were conducted under three conditions:

1. A flat ski (clamped and thus pressed to the ground; zero deflection)

2. The standard ISO ski-deflection (a distance between the supports of $150 \mathrm{~cm}$ and a deflection of $6 \mathrm{~cm}$; Fig. 4)

3. An extreme ski-deflection (a distance between the supports of $110 \mathrm{~cm}$ and a deflection of $6 \mathrm{~cm}$; Fig. 4)

Each test was repeated until three consecutive measurements with equivalent release values were achieved. Only consistent tests were used for further analysis. In practice, no more than one additional "pre-test" was necessary to yield consistency. Consistency was visually judged from the measurement curves that were plotted one over another in real time. 
The vertical force and the heel displacement were recorded for the forward bending release. In the torsion release test, the torque and the toe piece angle were recorded. The vertical force and the lever of $0.31 \mathrm{~m}$ (sole length) were used to calculate the present forward bending torque (My) as shown on Fig. 3. For both torque parameters, peak values were calculated in each test. In addition, the tests were alternatively recorded at high speed $(200 \mathrm{~Hz})$ or Full High definition $(50 \mathrm{~Hz})$ video recording for visual inspection.

Results are reported as mean and standard deviations. Statistical analysis was performed by one-way Analysis of variance (ANOVA), followed by multiplecomparison Tukey post hoc test. The level of statistical significance was set to $p<0.05$. Data were analysed in Matlab 7.5 software environment (MathWorks, Natick, MA, USA).

\section{Results}

\subsection{Forward Release}

The binding's releases occurred at the peak force values $(\mathrm{Fz})$ in force-displacement data (forward bending release) for the three different mountings of bindings at three different deflection conditions. The descriptive statistic along with one-way ANOVA and Tukey's post hoc test for the release values are presented in Table 1. The mean Fz values ranged from 1019.6 N (flat ski, original plate) to $1114.7 \mathrm{~N}$ (ISO-standard deflection, no plate) with standard deviation ranging from $0.6 \mathrm{~N}$ to $2.9 \mathrm{~N}$. The analysis of variance revealed significant effect of mounting types (no plate, original and new plate) on forward bending release. Post hoc comparison using Tukey's test indicated that the mean score among all pairs, except no plate versus new plate under flat ski and extreme-deflection conditions, were significantly different.

The relative differences (mean and standard deviation) between the peak My values for the flexed versus the flat ski are presented in Fig. 5. The observed mean differences range from 6.9 to $8.1 \%$ for the standard ISO ski-deflection and from 3.3 to $8.2 \%$ for the extreme ski-deflection.

With an increase in the release load being less than $9 \%$ for all three mounting conditions and for both ski-deflections, it becomes obvious that neither the first nor the second variables are of major importance for the release characteristics of the binding tested. This interpretation is supported by the fact that a deviation of up to $15 \%$ in the release load is accepted in all corresponding ISO standards in the official retailer setting procedures ("inspection tolerance"). It is interesting to see in Fig. 5 that the best performance (lowest difference compared to the test condition "flat") is shown for the binding mounted without any plate under the extreme bending condition. 
Table 1 Comparison between mean values of forward bending release (My) and torsion release $(\mathrm{Mz})$ under three different deflection conditions for three different mountings of the binding

\begin{tabular}{l|l|l|l|l|l|l|l}
\hline \multirow{2}{*}{ Test } & $\begin{array}{l}\text { Deflection } \\
\text { condition }\end{array}$ & $\begin{array}{l}\text { No plate } \\
n=3\end{array}$ & $\begin{array}{l}\text { Original } \\
\text { plate } n=3\end{array}$ & $\begin{array}{l}\text { New plate } \\
n=3\end{array}$ & $F$ & $p$ & $\begin{array}{l}\text { Tukey } \\
\text { post hoc }\end{array}$ \\
\hline $\begin{array}{l}\text { My } \\
(\mathrm{Nm})\end{array}$ & Flat ski & $\begin{array}{l}319.64 \\
(0.18)\end{array}$ & $\begin{array}{l}316.01 \\
(0.41)\end{array}$ & $\begin{array}{l}320.91 \\
(0.9)\end{array}$ & 56.53 & $<0.001$ & 1,3 \\
\cline { 2 - 8 } & ISO & $\begin{array}{l}345.56 \\
(0.87)\end{array}$ & $\begin{array}{l}337.89 \\
(0.61)\end{array}$ & $\begin{array}{l}344.99 \\
(0.55)\end{array}$ & 115.13 & $<0.001$ & 1,3 \\
\cline { 2 - 8 } & Extreme & $\begin{array}{l}330.15 \\
(0.32)\end{array}$ & $\begin{array}{l}341.81 \\
(0.64)\end{array}$ & $\begin{array}{l}344.31 \\
(0.56)\end{array}$ & 617.49 & $<0.001$ & $1,2,3$ \\
\hline $\mathrm{Mz}$ & Flat ski & $\begin{array}{l}79.46 \\
(0.37)\end{array}$ & $\begin{array}{l}80.69 \\
(0.38)\end{array}$ & $\begin{array}{l}82.89 \\
(0.24)\end{array}$ & 78.59 & $<0.001$ & $1,2,3$ \\
& & $\begin{array}{l}80.27 \\
(0.12)\end{array}$ & $\begin{array}{l}87.17 \\
(0.25)\end{array}$ & $\begin{array}{l}81.59 \\
(0.3)\end{array}$ & 736.63 & $<0.001$ & $1,2,3$ \\
& ISO & $\begin{array}{l}81.62 \\
(0.38)\end{array}$ & $\begin{array}{l}85.45 \\
(0.06)\end{array}$ & $\begin{array}{l}81.62 \\
(0.16)\end{array}$ & 252.62 & $<0.001$ & 1,3 \\
\cline { 2 - 8 } & Extreme & & & & & \\
\hline
\end{tabular}

Means and standard deviations (in parentheses), ANOVA results and significant differences based on Tukey's post hoc analysis. $n=$ sample size; $F=$ ANOVA $F$-statistics; $p=$ level of significance for ANOVA; ISO = ISO deflection condition $(150 \mathrm{~cm})$; Extreme $=$ extreme-deflection condition $(110 \mathrm{~cm})$; Significant differences based on Tukey post hoc test between the three mounting conditions are indicated by numbers: $1=$ no plate versus original plate; $2=$ no plate versus new plate; $3=$ original plate versus new plate

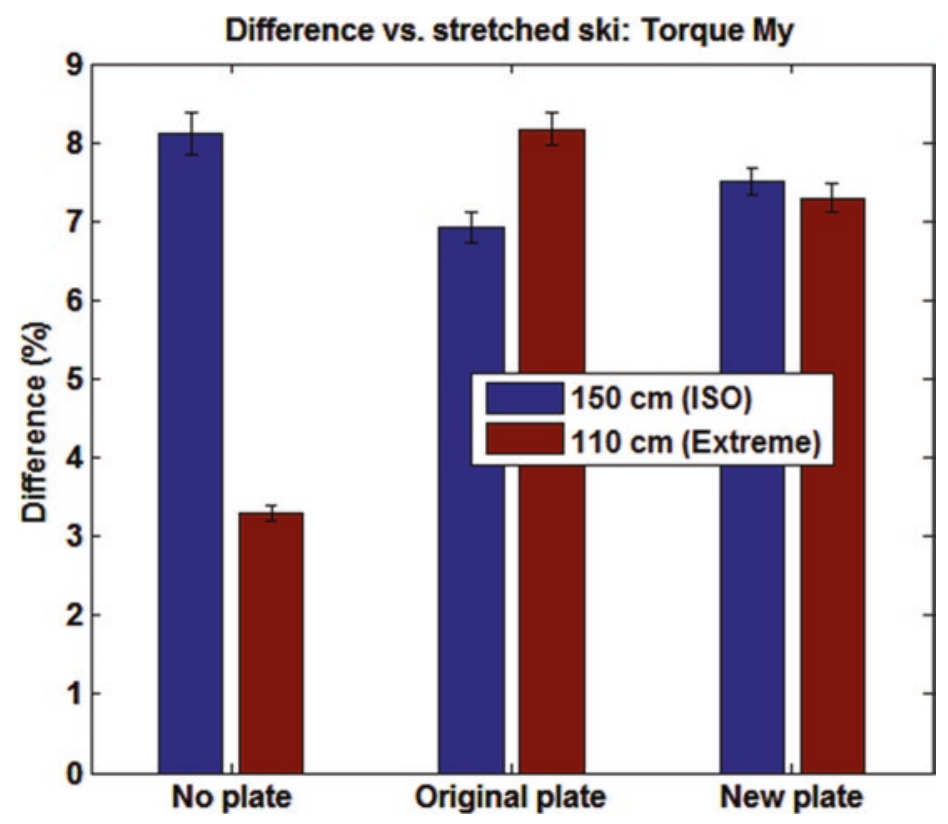

Fig. 5 Mean relative difference (ski-deflected versus stretched ski) in peak My torque values for the binding mounted directly on the ski (no plate), on the original and on the new ski plate under the two testing conditions: ISO-standard ski-deflection (a support distance of $150 \mathrm{~cm}$ ) and an extreme skideflection (a support distance of $110 \mathrm{~cm}$ ). The error bars represent standard deviations 


\subsection{Torsion Release}

Similarly as in forward bending release test, the binding's torsion releases occurred at the peak torque values $(\mathrm{Mz})$ in torque-angle data (forward bending release) for the three different mountings of bindings at three different deflection conditions. The descriptive statistic along with one-way ANOVA and Tukey's post hoc test for the torque release values are also presented in Table 1 . The mean Mz values ranged from $79.46 \mathrm{Nm}$ (flat ski, no plate) to $87.17 \mathrm{Nm}$ (ISO-standard deflection, original plate) with standard deviation ranging from 0.06 to $0.39 \mathrm{Nm}$. The analysis of variance revealed significant effect of the mounting condition (no plate, original and new plate) on torsion release. Post hoc comparison using Tukey's test indicated that the mean score among all pairs, except no plate versus new plate under extremedeflection condition, were significantly different.

The relative differences (mean and standard deviation) between the peak $\mathrm{Mz}$ values for the deflected versus the flat ski are presented in Fig. 6. The observed mean differences range from -1.6 to $+8.0 \%$ in the standard ISO ski-deflection, while they range from -1.5 to $+5.9 \%$ for the extreme ski-deflection. The relative peak difference was overall highest for the original plate in both testing conditions and lowest for the new ski plate.

\section{Discussion}

The main findings of the study are that the new designed ski plate, where the middle main part of the plate is "floating" on rocker arms, (1) improves the torsion release consistency of the ski binding when the ski is deflected, and (2) has no positive effect on the forward release.

The study examined an effect of the specially designed "Allflex" ski plate on the release behaviour of an Elan ER 17.0 Free Flex PRO ski binding. In order to elucidate the effect, the mounting of the ski bindings on the above-mentioned plate was compared to the mounting without any additional ski plate and to the mounting on the original supplemented ski plate. For this purpose, an ISO-standard loading device for testing ski bindings release was used. Three ski-deflection conditions (1) flat ski, (2) ski deflected according to ISO 9462:2014, and (3) ski-deflection exceeding the ISO condition were distinguished.

All three different ski binding mounting conditions resulted in release values which remained within the tolerances given by the ISO-standard for both release tests. This also holds true for the extreme deflected ski test condition, which is not a part of the ISO-standard. Despite that, one-way ANOVA with Tukey post hoc test (Table 1) revealed that all comparisons among different mountings of the binding under three conditions, except no plate versus new ski plate in forward bending release (ISO and extreme-deflection) and in torsion release (extreme ski-deflection), were significantly different from each other. These results should be interpreted that 


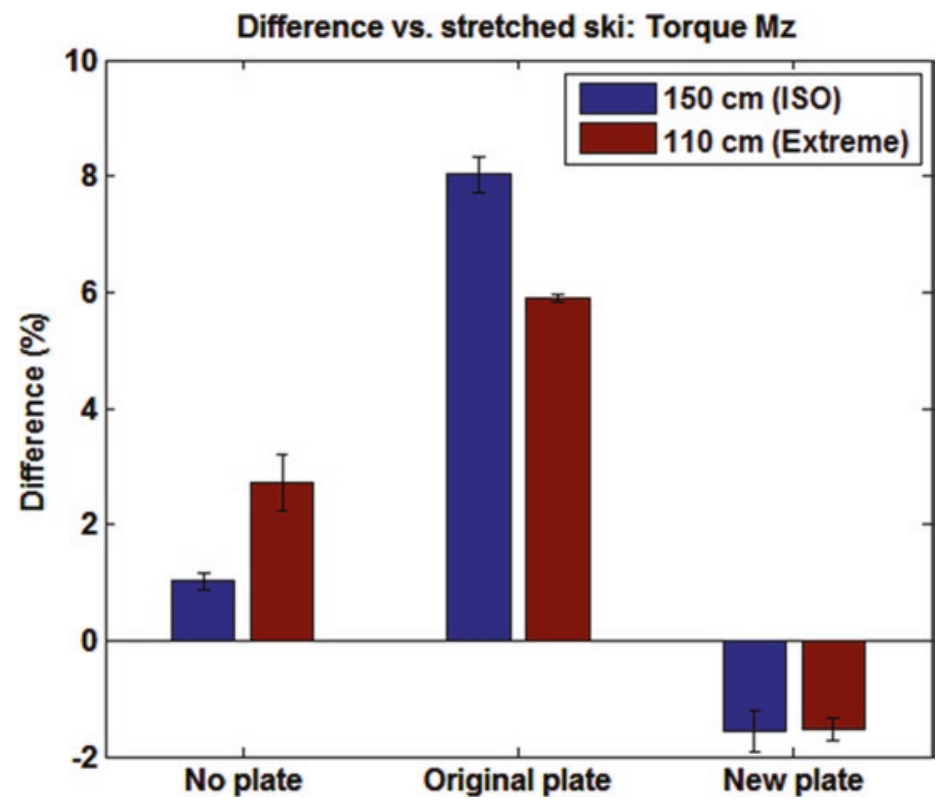

Fig. 6 Mean relative difference (ski-deflected versus flat ski) in peak torque Mz values for the binding mounted directly on the ski (no plate), on the original and on the new plate under the two testing conditions: ISO-standard ski-deflection (a support distance of $150 \mathrm{~cm}$ ) and an extreme skideflection (a support distance of $110 \mathrm{~cm}$ ). The error bars represent standard deviations

bindings in the same conditions (mounting and deflection) behaved very consistently, i.e. with small variance.

Despite the procedure of adjusting the bindings' releases by a series of test, significant differences in the baseline were observed, i.e. comparing the release values when the ski was set flat on the ground on both tests (Table 1). However, these differences were small, $<5 \mathrm{Nm}$ in forward bending and $<3.5 \mathrm{Nm}$ in torsion release, which is in the range of possible manipulation in the manual settings. Still, the differences in the baseline may influence the interpretation of the results comparing release consistency among mounting types. For this reason, relative differences between the releases values for the flexed versus the flat ski were more intensely analysed (Figs. 5 and 6) and some important differences between the mountings in the results were observed, especially with respect to the torsion release.

Torsion release under both, ISO and extreme-deflection, was very consistent with the binding mounted on the new ski plate, showing a negligible reduction of $\sim-1.5 \%$ compared to the flat condition. Interestingly, mounting directly on the ski was the second most consistent and superior to the mounting on the original (supplemented) ski plate. This result demonstrated that the ski plate may either improve or even spoil the release consistency.

Even though the detected improvements in relative torsion release consistency of bindings mounted on the new plate design were small, they still can be interpreted 
as a contribution to binding safety. As severe combined loading conditions were not tested in the current study, i.e. ski being deflected and at the same time twisted about its longitudinal axis (due to edging moment or "roll loading"), the safety gain by the new plate design might even be higher.

Based on the message of the Signal Detection Theory [19, 21], an increase in release consistency can be interpreted as a decrease in the probability of both inadvertent and also of the false release under the condition that the binding settings are appropriate [18]. This finding regarding the torsion release is of great importance because it is known that in both, recreational as well as competitive skiing, the largest number of injuries is related to the lower extremities, particularly to the knee joint [12-14]. For the knee joint it was found that both, internal and external rotations of the ski, are associated with knee injury mechanisms [22-24].

Even though all three mountings of the bindings under the ISO-standard deflection condition in forward bending release test demonstrated almost identical relative differences, their absolute values in most cases differed significantly. In contrast to torsion release, the specially designed ski plate did not improve the forward bending release consistency to a meaningful magnitude compared to other two types of mountings. A video analysis of the release behaviour revealed that the (upward directed) Fz vertical force (during forward bending release) caused to bend and stretch the middle floating part of the new ski plate away from the ski. This observation was in line with the fact that the set-up used in the current study with pulling at the heel does not adequately simulate typical real situation in skiing, as it neglects the body weight component. This however is also true for the test procedure according to ISO 9462:2014 (section 6.3.3). It is not well known even among experts that this release test with ski under deflection contains a rather critical simplification, which might significantly change the behaviour of the system. In real skiing, the force that deflects the ski is applied through the boot to the binding and then to the ski, whereas in the current ISO test, the deflection of the ski is forced "... by a strap or clamp, which does not interfere with the binding" (ISO 9462:2014, section 6.3.3.2 Testing). To the authors' knowledge, there is still no standard test procedure available offering satisfactory external validity.

Interestingly, the mounting of the binding with its own inbuilt "Free Flex system" directly on the ski outperformed the other two in an extreme-deflection condition. This indicates that adding ski plates does not necessarily improve the overall release behaviour. Even more, the overall results (relative differences) for the bindings mounted on the original plate were less consistent compared to the mounting directly on the ski.

The main limitation of the study was that only one type of skis, namely, Elan slalom skis, were used for all three mountings of the ski bindings in the testing protocol. It can be expected that at least the forward bending release could be dependent on the skis' longitudinal stiffness. This means that a less longitudinally stiff ski may flex more when the Fz vertical force is applied (forward bending release) compared to a stiffer ski and thus alter the results. However, the difference can be estimated as small, if not negligible according to the fixation of the ski in the testing 
procedure (see Fig. 4). Hence, possible effect of the small differences in the selected skis for the current study can be concluded to be even smaller. In addition, one type of ski bindings was used for tests, and it is possible that other binding models and/ or brands may behave differently. However, these bindings are a standard set together with the skis used in the current study.

Another limitation of the study was the problems of drawing conclusions based on laboratory tests when compared to real skiing situations where numerous factors may play a role and very different injury mechanisms are possible [6, 18, 25-27]. Nevertheless, a state-of-the-art measuring and testing device at an experienced and certified test house was employed for the experiment to ensure reliable and valid measurements.

The test protocol in this study did not investigate the effect of combined loads, which may be present in case of a twisted forward fall. For that reason ISO 9462: 2014 foresees a release test under combined loading (section 6.3.4). According to this standard, the influence of a forward lean of the body should not exceed $35 \%$, the influence of a backward lean no more than $25 \%$, the influence of a "roll loading" no more than $20 \%$ and the influence of an axial force no more than $15 \%$ of the reference value (a single axis loading condition). Interestingly, these ISO tests for combined loads are not united with those tests for the ski under deflection. In practice however, this situation may occur, for instance when a skier runs into a bump falling forward with a rotational component and the ski being strongly flexed at the same time. It is very likely that the new ski plate might demonstrate its additional safety margin under such extreme (but not rare) conditions.

In conclusion, mounting of ski bindings on specially designed ski plates may result in an improved release behaviour and thus potentially increase skiing safety. However, it should be noted that optimizing the consistency of one type of the release behaviour does not necessarily improve the overall ski bindings release behaviour. Even more, mounting of ski bindings on the ski plates can even decrease the release consistency (and skiing safety) as it was the case with the original (supplemented) ski plate. We suggest caution to skiers when combining different brands and types of skis, ski plates and ski bindings in order to avoid compromising skiing safety.

Acknowledgments We would like to express our gratitude to Aco Sitar, the "father" of the Allflex ski plate, Thomas Maier at TÜV Product Service GmbH in Munich, Matej Božičnik and Luka Grilc at Elan d.d.

\section{References}

1. Vanat L (2016) International report on snow \& mountain tourism—overview of the key industry figures for ski resorts; 8th edition. Available from http://www.vanat.ch/RM-world-report2016-vanat.pdf. Accessed 12 Jul 2016

2. Supej M, Kipp R, Holmberg HC (2011) Mechanical parameters as predictors of performance in alpine World Cup slalom racing. Scand J Med Sci Sports 21(6):e72-e81 
3. Federolf PA (2012) Quantifying instantaneous performance in alpine ski racing. J Sports Sci 30(10): 1063-1068

4. Supej M (2008) Differential specific mechanical energy as a quality parameter in racing alpine skiing. J Appl Biomech 24(2):121-129

5. Gilgien $\mathrm{M}$ et al (2014) Mechanics of turning and jumping and skier speed are associated with injury risk in men's World Cup alpine skiing: a comparison between the competition disciplines. Br J Sports Med 48(9):742-747

6. Sporri $\mathrm{J}$ et al (2012) Perceived key injury risk factors in World Cup alpine ski racing-an explorative qualitative study with expert stakeholders. Br J Sports Med 46(15):1059-1064

7. Sporri J et al (2016) Sidecut radius and the mechanics of turning-equipment designed to reduce risk of severe traumatic knee injuries in alpine giant slalom ski racing. Br J Sports Med 50(1):14-19

8. Sporri J et al (2012) Course setting and selected biomechanical variables related to injury risk in alpine ski racing: an explorative case study. Br J Sports Med 46(15):1072-1077

9. Haaland B et al (2016) Injury rate and injury patterns in FIS World Cup Alpine skiing (20062015): have the new ski regulations made an impact? Br J Sports Med 50(1):32-36

10. Hebert-Losier K, Holmberg HC (2013) What are the exercise-based injury prevention recommendations for recreational alpine skiing and snowboarding? A systematic review. Sports Med 43(5):355-366

11. Hunter RE (1999) Skiing injuries. Am J Sports Med 27(3):381-389

12. Flørenes TW et al (2009) Injuries among male and female World Cup alpine skiers. Br J Sport Med 43(13):973-978

13. Brucker PU et al (2014) Recreational and competitive alpine skiing: typical injury patterns and possibilities for prevention. Unfallchirurg 117(1):24-32

14. Burtscher $\mathrm{M}$ et al (2008) Effects of modern ski equipment on the overall injury rate and the pattern of injury location in Alpine skiing. Clin J Sport Med 18(4):355-357

15. Johnson RJ, Ettlinger CF, Shealy JE (2009) Update on injury trends in alpine skiing. In: Johnson RJ, Shealy JE, Langran M (eds) Skiing trauma and safety, vol 17. ASTM International, West Conshohocken, PA, pp 11-22

16. Kim S et al (2012) Snowboarding injuries: trends over time and comparisons with alpine skiing injuries. Am J Sports Med 40(4):770-776

17. Ruedl G et al (2011) ACL injury mechanisms and related factors in male and female carving skiers: a retrospective study. Int J Sports Med 32(10):801-806

18. Senner V et al (2013) Technical possibilities for optimising the ski-binding-boot functional unit to reduce knee injuries in recreational alpine skiing. Sports Eng 16(4):211-228

19. Shealy J, Ettlinger C, Johnson R (2005) Using signal detection theory as a model to evaluate release/retention criteria in alpine skiing. J ASTM Int 2(7):1-12

20. Sitar F (2008) Platform for mounting a ski binding on a ski. European Patent Office, EP2285457, PCT/SI2008/000068, E.P. Office

21. Shealy JE, Ettlinger CF (1999) A model for evaluation release/retention criteria in alpine skibinding-boot systems. In: Johnson RJ (ed) Skiing trauma and safety, vol 12. ASTM International, West Conshohocken, PA, pp 120-131

22. Paletta GA Jr et al (1992) Patterns of meniscal injury associated with acute anterior cruciate ligament injury in skiers. Am J Sports Med 20(5):542-547

23. Jarvinen $M$ et al (1994) Mechanisms of anterior cruciate ligament ruptures in skiing. Knee Surg Sports Traumatol Arthrosc 2(4):224-228

24. Krosshaug $\mathrm{T}$ et al (2007) Biomechanical analysis of anterior cruciate ligament injury mechanisms: three-dimensional motion reconstruction from video sequences. Scand J Med Sci Sports 17(5):508-519

25. Rust DA, Gilmore CJ, Treme G (2013) Injury patterns at a large Western United States ski resort with and without snowboarders: the Taos experience. Am J Sports Med 41(3):652-656 
26. Stenroos A et al (2015) Tibial fractures in alpine skiing and snowboarding in Finland: a retrospective study on fracture types and injury mechanisms in 363 patients. Scand J Surg 105(3):191-196. doi:10.1177/1457496915607410

27. Urabe $Y$ et al (2002) Anterior cruciate ligament injury in recreational alpine skiers: analysis of mechanisms and strategy for prevention. J Orthop Sci 7(1):1-5

Open Access This chapter is distributed under the terms of the Creative Commons AttributionNoncommercial 2.5 License (http://creativecommons.org/licenses/by-nc/2.5/) which permits any noncommercial use, distribution, and reproduction in any medium, provided the original author(s) and source are credited.

The images or other third party material in this chapter are included in the work's Creative Commons license, unless indicated otherwise in the credit line; if such material is not included in the work's Creative Commons license and the respective action is not permitted by statutory regulation, users will need to obtain permission from the license holder to duplicate, adapt or reproduce the material.

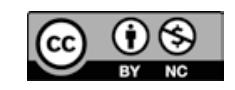

